\title{
Impacto da gestão de custos na formação do preço de venda: o caso de uma Clínica Dermatológica
}

Rodrigo Fernandes Malaquias
Mestrado em Administração pela Universidade Federal de Uberlândia - UFU Av. João Naves de Ávila, 2121. Santa Mônica. Uberlândia/MG E-mail: rodrigofmalaquias@yahoo.com.br

Virginia Aparecida Castro Mestrado em Administração pela Universidade Federal de Uberlândia - UFU Rua Bocaiúva, 82, Morada da Colina. Uberlândia/MG E-mail: virginiaconsultoria@yahoo.com.br

Tânia Regina Brasileiro Azevedo Teixeira Doutorado em Administração de Empresas pela Fundação Getúlio Vargas - FGV Professor da Universidade Federal de Uberlândia/MG Av. João Naves de Ávila, 2121 Bloco IF - Sala 216. S. Mônica. Uberlândia/MG

E-mail: taniateixeirabr@yahoo.com.br

\section{RESUMO}

Os preços de venda de produtos de uma empresa podem ser fixados com base nos custos, no mercado ou em uma combinação de ambos. Neste artigo tem-se por objetivo geral identificar as diferenças entre os preços praticados com base no mercado e os preços baseados na estrutura de custos das empresas. Para tanto, realizou-se um estudo de caso em uma clínica dermatológica que realiza atendimentos clínicos, estéticos e cirúrgicos situada na região do Triângulo Mineiro. A clínica atua com pioneirismo e tem destaque no mercado nacional principalmente pela competência do corpo clínico e pelos altos investimentos em tecnologia de ponta, possuindo um dos mais modernos e avançados Centros de Laser do país. Os resultados obtidos mostram que as duas formas de determinação do preço de venda - com base em custos e com base no mercado - geram valores diferentes e incoerentes. Os impactos dessas diferenças para a gestão desta clínica, no tocante à contribuição para a competitividade, além de uma possível política de descontos, também são pontos comentados no artigo.

Palavras-chave: Gestão de custos. Preço de venda. Clínicas dermatológicas. Centro de laser.

Impact of cost management in the formation of the selling price: the case of a Dermatology Clinic 
Impacto da gestão de custos na formação do preço de venda: o caso de uma Clínica

Dermatológica

Rodrigo Fernandes Malaquias, Virginia Aparecida Castro, Tânia Regina Brasileiro Azevedo Teixeira

\section{ABSTRACT}

The selling prices of a company may be set based on costs, the market or in a combination of both. This paper aims to identify the differences between market-based prices and prices based on the cost structure of enterprises. For both, there was a case study in a dermatological clinic that performs medical consultations, cosmetic and surgical situated in the Triângulo Mineiro region. The clinic works with pioneering spirit and are highlighted in the domestic market mainly by the competence of clinical staff and the high investments in technology, owning one of the most modern and advanced Laser Centers of the country. The results show that the two ways of determining the selling price - cost-based and market-based - generate different values. The impacts of these differences for the management of this clinic, in terms of contribution to competitiveness, and a possible discount policy, are discussed in paper.

Key-words: Cost management. Selling price. Dermatology clinic. Laser center.

\section{INTRODUÇÃO}

Os consumidores têm se mostrado cada vez mais exigentes, buscando produtos e serviços com qualidade e preços adequados, o que acaba por obrigar as organizações a ficarem cada vez mais atentas ao mercado (FARIA; SCHLINDWEIN; KLANN, 2006). Por outro lado, os preços praticados pelas empresas devem ser suficientes para cobrir seus custos, despesas, e ainda apresentar um retorno sobre o capital aplicado no empreendimento (CALLADO et. al., 2005).

Segundo Martins (2008, p. 218), os preços de venda de uma empresa podem ser fixados: "com base nos custos, no mercado ou em uma combinação de ambos". No entanto, tem-se que a fixação de preços com base unicamente no mercado pode não ser coerente com a realidade interna da empresa e, consequentemente, com sua estrutura de custos.

Identificou-se, na região do Triângulo Mineiro, uma clínica dermatológica que possui um avançado Centro de Laser que, para formação de seu preço de venda, baseava-se apenas no preço praticado pelo mercado. 
Impacto da gestão de custos na formação do preço de venda: o caso de uma Clínica

Neste contexto, levantou-se a seguinte questão de pesquisa: Qual a diferença entre o preço de venda formado com base no mercado e o preço de venda baseado na estrutura de custos para clínicas dermatológicas?

Escolheu-se para o estudo empírico a clínica mencionada, pois a mesma encontra-se em fase de transição em sua estrutura de gerenciamento de preços e custos. Desta forma, o presente artigo tem por objetivo geral identificar as diferenças entre os preços praticados com base no mercado e os preços baseados na estrutura de custos das empresas. Como objetivo específico pretende-se analisar se após o conhecimento de sua estrutura de custos, os preços praticados pela clínica devem sofrer alterações significativas.

\section{REVISÃO DA LITERATURA}

Custeio, segundo Martins (2008), significa apropriação de custos. Segundo o citado autor, o custeio por absorção é um método derivado da aplicação dos Princípios Fundamentais de Contabilidade. Consiste, basicamente, na apropriação de todos os custos de produção aos bens fabricados pela empresa. Por outro lado, segundo outro método de custeio, o custeio variável, somente se apropriam aos produtos fabricados pela empresa os custos variáveis, quer eles sejam diretos ou indiretos. Deste modo, "o custo dos produtos vendidos e os estoques finais de produtos em elaboração e produtos acabados só conterão custos variáveis" (VICECONTI; NEVES, 1995, p. 85). Nesta forma de custeio, tratam-se os custos fixos da mesma maneira que as despesas incorridas no período; ou seja, os custos fixos são contabilizados no resultado do período em que incorreram, independente da venda dos produtos que a empresa tenha fabricado ou estocado.

Para o estudo de caso utilizou-se o método de custeio por absorção, descrito a seguir. Além disso, utilizou-se o conceito do custo de oportunidade, que é abordado também neste referencial teórico. 
Impacto da gestão de custos na formação do preço de venda: o caso de uma Clínica

Dermatológica

Rodrigo Fernandes Malaquias, Virginia Aparecida Castro, Tânia Regina Brasileiro Azevedo Teixeira

\subsection{Custeio por absorção}

Segundo Viceconti e Neves (1995), a metodologia de custeio por absorção consiste na alocação de todos os custos ocorridos no período à produção do respectivo período, sejam eles fixos ou variáveis. "Todos os gastos relativos ao esforço de produção são distribuídos para todos os produtos ou serviços feitos" (MARTINS, 2008, p. 37). Ou seja, todos os custos relacionados à produção dos itens fabricados por uma empresa devem ser apropriados aos produtos, sejam eles fixos ou variáveis em relação ao volume de produção. Ao se adotar esta metodologia, conforme esclarece Leone (2000), os custos dos produtos estarão absorvendo todos os custos de fabricação; daí a sua denominação, custeio por absorção. Os gastos relacionados a outros departamentos, que não os de produção, são considerados como despesas; consequentemente, não são alocadas aos produtos, sendo seus montantes integrais contabilizados diretamente no resultado do período analisado.

Os custos dos produtos fabricados, depois de devidamente alocados, só farão parte do resultado do período quando o produto final for vendido. Antes de sua venda, estes custos apresentam-se contabilizados na conta de estoques da empresa.

Uma das vantagens do custeio por absorção sobre os demais métodos de custeio está na sua aceitação pela Auditoria Externa e pela legislação do Imposto de Renda (VICECONTI; NEVES, 1995), pois tal método de custeio atende ao regime de competência. A Lei 6.404/76, em seu artigo 177, prevê que a empresa deverá "registrar suas mutações patrimoniais segundo o regime de competência" (BRASIL, 1976). Tal regime tem por base o princípio de competência, fundamentado pelo artigo 9o da resolução 750/93 do Conselho Federal de Contabilidade. De acordo com a definição do princípio de competência dada pela citada resolução, "as receitas e as despesas devem ser incluídas na apuração do resultado do período em que ocorrerem [...] independentemente de recebimento ou pagamento" (CONSELHO FEDERAL DE CONTABILIDADE, 1993). Ao contabilizar na Demonstração de Resultados do Exercício somente os custos referentes aos produtos vendidos, o custeio por absorção atende ao regime de competência. 
Impacto da gestão de custos na formação do preço de venda: o caso de uma Clínica

Dermatológica

Rodrigo Fernandes Malaquias, Virginia Aparecida Castro, Tânia Regina Brasileiro Azevedo Teixeira

A apropriação de todos os gastos de produção aos produtos, como especificado inicialmente, consiste na alocação de dois tipos de custos: as variáveis e os fixos. Os custos variáveis são apropriados unitariamente aos produtos, pois, como a própria definição já esclarece, a determinação de quanto pertence a cada produto é objetiva, pois os mesmos variam conforme a produção. Já os custos fixos necessitam de algum critério para que sejam alocados à produção. Este critério é denominado de rateio. $\mathrm{O}$ rateio consiste na distribuição dos custos fixos aos produtos, que podem basear-se nas quantidades produzidas no período, no consumo de horas de mão-de-obra, quantidade de matéria-prima, etc. Ao optar por uma das opções disponíveis, o profissional de contabilidade deve "procurar entre as diferentes alternativas a que traz consigo menor grau de arbitrariedade" (MARTINS, 2008, p. 56). De acordo com Vicenconti e Neves (1995) e Martins (2008), o critério de rateio pode se tornar mais preciso quando se adota a departamentalização para a distribuição dos custos.

Nas empresas que usam o custeio por departamentalização, os gastos gerais de fabricação são primeiramente alocados aos departamentos e somente depois atribuídos aos produtos. [...] a departamentalização consiste em dividir a fábrica em segmentos, chamados departamentos, aos quais são debitados todos os custos de produção neles incorridos (VICECONTI; NEVES, 1995, p. 43-45).

Martins (2008, p. 65) esclarece que "departamento é a unidade mínima administrativa para a contabilidade de custos, representada por pessoas e máquinas (na maioria dos casos), em que se desenvolvem atividades homogêneas". Entende-se, então, como departamento uma unidade dentro da empresa ou um setor, composto por homens e/ou máquinas que desenvolvem atividades de mesmo caráter, por exemplo: almoxarifado, manutenção, supervisão da fábrica, etc. Estes departamentos dividem-se em dois grandes grupos: "os que promovem qualquer tipo de modificação sobre o produto diretamente e os que nem recebem o produto" (MARTINS, 2008, p. 66). Os departamentos que promovem modificação sobre os produtos são denominados 
Impacto da gestão de custos na formação do preço de venda: o caso de uma Clínica

Dermatológica

Rodrigo Fernandes Malaquias, Virginia Aparecida Castro, Tânia Regina Brasileiro Azevedo Teixeira

departamentos de produção. Os que não promovem tal modificação direta sobre os produtos são chamados de departamentos de serviços.

No Apêndice A, pode-se verificar o esquema básico do custeio por absorção, indo desde a separação entre os custos e as despesas na empresa até a apuração do resultado do período. Considera-se que, neste exemplo, a empresa apresenta quatro departamentos, sendo dois de serviço e dois de produção. Sua linha de produção resume-se à industrialização dos produtos $X$ e $Y$. Ainda no Apêndice $A$, pode-se interpretar o regime de competência da seguinte forma: o resultado do exercício compreende somente a receita auferida, as despesas incorridas e os custos de fabricação realizados no período.

\subsection{Custo de oportunidade}

Segundo Troster e Mochón (1999) e Vasconcelos e Garcia (2000), o custo de oportunidade representa-se pela perda de capacidade de produção de um bem $\mathrm{A}$ em prol do aumento da capacidade de produção de um bem B. Neves (1982) trata tal custo como a taxa de juros que a empresa pode obter em aplicações externas de capital e a ela acessíveis. Tem-se então que uma opção de investimento se mostrará atraente se esta conseguir remunerar seus detentores de capital próprio a uma taxa acima da oferecida pelo custo de oportunidade do capital investido.

O conceito de custo de oportunidade é proveniente da Teoria Econômica e, conforme Pereira e Oliveira (2006), foi Frederich Von Wieser (1851-1926) quem originalmente o empregou para mensuração do valor econômico dos fatores de produção. Segundo a concepção deste autor, "o custo de oportunidade de um fator de produção representa a renda líquida gerada por este fator em seu melhor uso alternativo" (PEREIRA; OLIVEIRA, 2006, p. 388). Araújo e Assaf Neto (2003, p. 22) esclarecem que este custo pode ser definido como "a melhor alternativa de investimento desprezada quando na escolha de um outro, de mesmo risco"; a rentabilidade da melhor alternativa de investimento não escolhida implica no custo de oportunidade. 
Impacto da gestão de custos na formação do preço de venda: o caso de uma Clínica

Dermatológica

Rodrigo Fernandes Malaquias, Virginia Aparecida Castro, Tânia Regina Brasileiro Azevedo Teixeira

Goulart (2002, p. 21) cita uma forma de raciocínio para a compreensão de seu conceito: "ao escolher, toma-se um curso de ação, abandonando outras alternativas que proporcionariam benefícios específicos". Ou seja, ao se escolher algo, normalmente ter-se-á de sacrificar outra coisa, representando esta alternativa desprezada o custo de oportunidade da alternativa escolhida. Goulart (2002, p. 21) ainda esclarece que "é interessante notar que, quando se escolhe algo, tem-se a tendência de olhar apenas para aquilo que foi obtido com a escolha, não se atentando para os benefícios que foram sacrificados pelo fato de não se ter escolhido outras alternativas". Complementa-se este raciocínio colocando-se que "o resultado de uma decisão decorre do confronto entre o benefício gerado pela alternativa escolhida e o benefício que seria obtido pela escolha da melhor alternativa abandonada" (PEREIRA; OLIVEIRA, 2006, p. 389).

Desta forma, o custo de oportunidade, visto como a remuneração de um investimento alternativo que poderia ser obtida pela empresa, apresenta potenciais benefícios para a avaliação de desempenho e resultados (CATELLI, 2006). Nesta abordagem, o conceito do custo estudado neste tópico é relevante para a determinação do resultado econômico apresentado pelas empresas, permitindo a "avaliação simultânea do desempenho organizacional e do valor da empresa" (REIS, 2002, p. 49). Desta forma, tal custo também foi levado em conta na apuração do custo dos serviços de dermatologia estética que se estuda neste artigo.

\subsection{Pesquisas sobre gestão e custos}

Macedo (1991), em seu estudo sobre encargos financeiros e formação do preço de venda, identificou um problema de classificação dos encargos financeiros incorridos pelas empresas na aquisição de insumos, o que impactaria na mensuração incorreta dos custos e, consequentemente, formação do preço de venda de uma maneira equivocada.

Lima, Egito e Silva (2004) destacam que, frente a um ambiente competitivo, o setor hoteleiro brasileiro tem se tornado cada vez mais competitivo. Para tanto, "este 
Impacto da gestão de custos na formação do preço de venda: o caso de uma Clínica

Dermatológica

Rodrigo Fernandes Malaquias, Virginia Aparecida Castro, Tânia Regina Brasileiro Azevedo Teixeira

ambiente gerou também a necessidade de ferramentas gerenciais adequadas para uma tomada de decisão eficaz, com o conhecimento de custos ganhando mais importância nesse contexto" (LIMA; EGITO; SILVA, 2004, p. 114), sendo, ainda na opinião dos autores, o conhecimento relativo aos custos fundamental para tomadas de decisão. Contudo, em uma pesquisa realizada nos hotéis de médio e grande porte do Rio Grande do Norte, os autores constataram que as ferramentas utilizadas na gestão hoteleira, no que se refere aos custos, são inadequadas para uma tomada de decisão eficaz.

Callado et al. (2005) desenvolveram um trabalho com o objetivo de analisar a gestão de custos e o processo de formação de preços das agroindústrias paraibanas. A pesquisa envolveu um estudo empírico com 20 empresas do setor da agroindústria. Constaram que a maioria das empresas possui sistema de custos ou alguma forma de estrutura de custos, e o responsável pelo registro dos custos do processo produtivo é o gerente. Contudo, os autores também identificaram "de modo geral, a pouca preocupação dos gestores no acompanhamento e controle dos custos de produção, uma vez que, face às dificuldades e necessidades enfrentadas, ainda não dispõem de um sistema de controle eficaz" (CALLADO et al., 2005, p. 8). O equivalente a $45 \%$ das empresas estudadas utiliza o método de custeio por absorção.

Aspectos metodológicos

Em linha com os trabalhos de Guerreiro e Santos (2006) e Santos (2007, p. 37), tem-se que "no Brasil, uma das principais reclamações dos pesquisadores da área de Ciências Contábeis é a total indisponibilidade de dados para a realização de pesquisas empíricas". Mesmo assim, conseguiu-se a abertura de uma empresa para a realização da presente pesquisa. Trata-se de uma clínica dermatológica, que possui um avançado Centro de Laser, situada na região do Triângulo Mineiro, que, para este trabalho, será denominada de Clínica Dermatológica ABC. Para a formação de seu preço de venda, tal empresa se baseava apenas no preço praticado por clínicas semelhantes, porém situadas em outro Estado, especificamente em São Paulo. 
Impacto da gestão de custos na formação do preço de venda: o caso de uma Clínica

Dermatológica

Rodrigo Fernandes Malaquias, Virginia Aparecida Castro, Tânia Regina Brasileiro Azevedo Teixeira

A temática deste trabalho relaciona-se aos impactos da gestão de custos na formação do preço de venda de serviços dermatológicos. O caso dessa clínica se mostrou adequado, por permitir uma comparação entre o preço de venda baseado no mercado e o preço de venda com base na estrutura de custos da empresa. As informações necessárias para a execução do trabalho foram obtidas a partir de um contato direto dos pesquisadores com a área responsável pela contabilidade e gestão da clínica. A pergunta de partida foi: qual a diferença entre o preço de venda formado com base no mercado e o preço de venda baseado na estrutura de custos dessas empresas?

Classificou-se a presente pesquisa como sendo um estudo descritivo que, segundo Andrade (2004), apresenta as características de uma determinada situação sem que o pesquisador nela interfira, permitindo sua observação sistemática, registro, análise e interpretação.

Neste trabalho, os pesquisadores coletaram as informações de acordo com 0 que já era praticado pela clínica - preço com base no mercado -. Além disso, foram coletados também os dados necessários para estimar o preço de venda com base na estrutura de custos que a empresa possui. Finalmente, foram comparados os resultados obtidos com o que já era praticado pela empresa, o que fundamenta a análise do trabalho.

\section{PANORAMA GERAL DA CLÍNICA DERMATOLÓGICA ABC}

A Clínica Dermatológica ABC está no mercado desde 1992. A empresa iniciou suas atividades por meio do trabalho dos médicos proprietários, sendo primordialmente uma empresa familiar. Com o passar dos anos, conseguiu espaço dentro do seu mercado de atuação, crescendo em faturamento e quantidade de pacientes.

Apresenta destaque no cenário nacional de clínicas dermatológicas principalmente pela competência técnica do corpo clínico e altos investimentos em 
Impacto da gestão de custos na formação do preço de venda: o caso de uma Clínica

tecnologia de ponta, possuindo um dos mais modernos e avançados Centros de Laser do país.

O corpo clínico é referência em termos de dermatologia no Brasil e conta com uma equipe preparada e atualizada, sendo presença nos Congressos Nacionais e Internacionais da área dermatológica.

Aos poucos o quadro de funcionários foi sendo ampliado, conforme as necessidades existentes e atualmente são 20 colaboradores entre coordenadora, enfermeiras, fisioterapeutas, técnicas de enfermagem, secretárias, atendentes entre outros.

A clínica possui um faturamento superior a $R \$ 100 \mathrm{mil} / \mathrm{mês}$, e o Centro de Laser possui mais de 10 equipamentos de alta tecnologia para prestar serviços voltados para a área dermatológica - clínica e estética -. O investimento no Centro de Laser é superior a $R \$ 1.000$ mil.

\section{RESULTADOS E ANÁLISE}

Um dos equipamentos do Centro de Laser é destinado ao tratamento da pele por meio da aplicação de disparos a laser nas regiões a serem tratadas, como mão, nariz, bochecha etc.

Para a formação do preço de venda de seus serviços, a Clínica $A B C$ procedia da seguinte maneira: fazia uma cotação dos serviços equivalentes prestados por empresas do mesmo ramo de atuação, situadas no estado de São Paulo. A partir dessas informações, ela determinava quais seriam os preços de venda de seus serviços. Essas informações eram atualizadas semestralmente. A Tabela 1, apresentada a seguir, mostra os tipos de serviços praticados pela Clínica $A B C$ e os seus preços baseados na cotação de mercado. 
Impacto da gestão de custos na formação do preço de venda: o caso de uma Clínica

Rodrigo Fernandes Malaquias, Virginia Aparecida Castro, Tânia Regina Brasileiro Azevedo Teixeira

Tabela 1: Tabela de preços dos serviços prestados pela Clínica ABC com base no mercado

\begin{tabular}{|c|c|}
\hline Área & $\begin{array}{c}\text { Preço do } \\
\text { Serviço (R\$) }\end{array}$ \\
\hline Antebraço & 650,00 \\
\hline Bochecha & 180,00 \\
\hline Buço & 180,00 \\
\hline Colo & 400,00 \\
\hline Face & 480,00 \\
\hline Mãos & 300,00 \\
\hline Nariz & 80,00 \\
\hline Olheira & 80,00 \\
\hline Pescoço & 300,00 \\
\hline Queixo & 180,00 \\
\hline
\end{tabular}

Fonte: Elaborado pelos autores

Após o conhecimento dos preços já praticados pela Clínica $A B C$, partiu-se para a identificação da quantidade de disparos necessários em cada área corporal. Estes números foram organizados na Tabela 2, apresentada a seguir. Trabalha-se com a média de disparos referente ao histórico de operação do aparelho que se utiliza para a realização dos disparos, nos últimos quatro anos. Estas informações foram obtidas junto à referida clínica. 
Impacto da gestão de custos na formação do preço de venda: o caso de uma Clínica

Rodrigo Fernandes Malaquias, Virginia Aparecida Castro, Tânia Regina Brasileiro Azevedo Teixeira

Tabela 2: Média de disparos gastos por área corporal

\begin{tabular}{|c|c|}
\hline Área & $\begin{array}{c}\text { Média de } \\
\text { disparos }\end{array}$ \\
\hline Antebraço & 292 \\
\hline Bochecha & 44 \\
\hline Buço & 69 \\
\hline Colo & 138 \\
\hline Face & 200 \\
\hline Mãos & 103 \\
\hline Nariz & 10 \\
\hline Olheira & 23 \\
\hline Pescoço & 119 \\
\hline Queixo & 69 \\
\hline
\end{tabular}

Fonte: Elaborado pelos autores

Com base nos dados fornecidos pela clínica $A B C$, observou-se que nos últimos quatro anos o aparelho havia realizado 117.744 disparos; dividindo-se esse valor por 41 meses - tempo de utilização do aparelho pela clínica - tem-se uma média estimada de 2.872 disparos por mês. Esse valor de disparos médios realizados por mês é o parâmetro adotado como critério de rateio; ao mesmo tempo, serve como meta de disparos mensais a ser atingida pela clínica.

Foi realizado então um levantamento, buscando-se identificar todos os custos fixos e variáveis que a clínica estava sujeita. A clínica possui 3 funcionárias responsáveis pelo atendimento no nível técnico, e 4 funcionárias responsáveis pelo atendimento geral da clínica. O gasto com salário das técnicas é mostrado na Tabela 3, a seguir. 
Impacto da gestão de custos na formação do preço de venda: o caso de uma Clínica Rodrigo Fernandes Malaquias, Virginia Aparecida Castro, Tânia Regina Brasileiro Azevedo Teixeira

Tabela 3: Gastos totais com salários das atendentes - nível técnico

\begin{tabular}{|c|c|c|c|c|}
\hline $\begin{array}{c}\text { Atendentes } \\
- \\
\text { Nível } \\
\text { Técnico }\end{array}$ & Salários - R\$ & $\begin{array}{c}\text { Encargos - } \\
\mathbf{R} \$ \\
\mathbf{( 3 7 , 3 \% )}\end{array}$ & $\begin{array}{c}\text { Férias e } \\
\mathbf{1 3} \text { - Salário - R\$\$ }\end{array}$ & Total - R\$ \\
\hline Técnica 01 & 870,00 & 324,51 & 232,27 & $1.426,78$ \\
\hline Técnica 02 & 870,00 & 324,51 & 232,27 & $1.426,78$ \\
\hline Técnica 03 & 750,00 & 279,75 & 232,27 & $1.262,02$ \\
\hline Total & $2.490,00$ & 928,77 & 696,80 & $4.115,57$ \\
\hline
\end{tabular}

Fonte: Elaborado pelos autores

Contudo, tal serviço técnico de atendimento não é realizado apenas para a aplicação dos disparos no aparelho estudado neste artigo. Nos últimos quatro anos, as técnicas realizaram um volume de 10.758 atendimentos; destes, 669 se referiram ao aparelho em análise, o que representa $6,22 \%$, ou seja, conforme a teoria apresentada poder-se-ia considerar esse critério de alocação de custos semelhante ao da departamentalização. Desta forma, do total de salários, $\mathrm{R} \$ 255,93(4.115,57 \times 6,22 \%)$ são alocados ao aparelho que se está analisando. Quanto aos gastos com salários das atendentes, a Tabela 4, a seguir, apresenta a situação da clínica.

Tabela 4: Gastos totais com salários das atendentes - nível atendimento geral

\begin{tabular}{|c|c|c|c|c|}
\hline $\begin{array}{c}\text { Atendentes } \\
- \\
\text { Nível Geral }\end{array}$ & Salários - R\$ & $\begin{array}{c}\text { Encargos - } \\
\mathbf{R \$} \\
\mathbf{( 3 7 , 3 \% )}\end{array}$ & $\begin{array}{c}\text { Férias e } \\
\mathbf{1 3} \text { Salário - R\$ }\end{array}$ & Total - R\$ \\
\hline Atendente 01 & 575,00 & 214,48 & 153,51 & 942,98 \\
\hline Atendente 02 & 575,00 & 214,48 & 153,51 & 942,98 \\
\hline Atendente 03 & 870,00 & 324,51 & 232,27 & $1.426,78$ \\
\hline Atendente 04 & 870,00 & 324,51 & 232,27 & $1.426,78$ \\
\hline Total & $2.890,00$ & $1.077,97$ & 771,55 & $4.739,52$ \\
\hline
\end{tabular}

Fonte: Elaborado pelos autores 
Impacto da gestão de custos na formação do preço de venda: o caso de uma Clínica

Dermatológica

Rodrigo Fernandes Malaquias, Virginia Aparecida Castro, Tânia Regina Brasileiro Azevedo Teixeira

Da mesma forma que o serviço de atendimento técnico, o serviço das atendentes não é dedicado somente ao atendimento do aparelho estudado. Nos últimos quatro anos, as atendentes realizaram 39.332 atendimentos; desses atendimentos, 669 se referiram ao aparelho em análise, o que representa 1,70\%. Assim, do total dos salários das atendentes, o valor de $\mathrm{R} \$ 80,61$ (4.739,52 x 1,70\%) será alocado ao aparelho em estudo.

O aluguel mensal da sala em que são realizados os atendimentos corresponde a $\mathrm{R} \$ 355,00$. A média da conta de energia elétrica consumida mensalmente pelo aparelho em estudo, nos últimos 12 meses, foi de $\mathrm{R} \$ 851,70 / \mathrm{mês}$.

Destaca-se que, à primeira vista, pode parecer que a participação do aparelho em estudo no total de atendimentos técnicos realizados pela clínica - que foi de 6,22\% e também no total de atendimentos de nível geral - que foi de $1,70 \%$ - não é significativa. Porém, há de se colocar que o oferecimento de serviços estéticos baseados em tratamentos a laser por essa clínica constituiu um diferencial para a mesma, pois poucas clínicas no Brasil - não mais que cinco - possuíam essa opção a ser oferecida aos seus pacientes, na época da aquisição do equipamento.

Além disto, com este diferencial, novos clientes são atraídos também para a realização de outros tratamentos estéticos na mesma clínica, o que gera impacto diretamente no faturamento bruto total da empresa.

Em relação à manutenção, estima-se conforme orientações do fornecedor do equipamento em estudo, que são necessárias duas visitas para assistência técnica por ano. Cada visita custa o equivalente a $R \$ 1.700,00$. Assim, o custo mensal dessas visitas seria equivalente a $R \$ 283,33$ - se são duas por ano, são gastos $R \$ 1.700,00$ a cada seis meses -.

Quando adquirido, o aparelho em estudo custou $R \$ 154.990,00$, e o fornecedor informou que o tempo de vida útil estimado seria de 120 meses. Desta forma, a depreciação mensal do aparelho foi calculada em $R \$ 1.291,58$, o que também faz parte da estrutura de custos fixos. Contudo, não houve investimentos somente nesse aparelho; as ponteiras que fazem os disparos a laser custaram $R \$ 13.200,00$ - esse 
Impacto da gestão de custos na formação do preço de venda: o caso de uma Clínica

custo entrará no custo variável -. Assim, a empresa mantém o equivalente a $R \$$ $168.190,00$ em equipamentos $(154.990,00+13.200,00)$; caso esse investimento fosse aplicado em um investimento alternativo, sem risco, como a caderneta de poupança que, na época, rendia $0,5 \%$ de juros ao mês, a empresa poderia obter a rentabilidade de $R \$ 840,95$, que também é considerada como um custo fixo.

Considerou-se que não se deveria eliminar dessa análise o custo de oportunidade, pois esta análise mostra como lucro que a atividade consegue gerar além daquilo que se obteria de juros aplicando o dinheiro em investimentos de baixo risco. Sem a consideração do custo de oportunidade, o custo representaria apenas o resgate do valor originalmente investido.

Desta forma, tornou-se possível calcular o custo fixo total ao qual a clinica $A B C$ estava sujeita. Tais números foram resumidos na Tabela 5 , a seguir.

Tabela 5: Custo fixo total da clínica ABC para o aparelho em estudo

\begin{tabular}{|c|c|}
\hline Custos fixos mensais & $\mathbf{R} \mathbf{}$ \\
\hline Aluguel da Sala & 355,00 \\
\hline Energia Elétrica & 851,70 \\
\hline Mão de obra Técnica & 255,93 \\
\hline Mão de obra de Atendimento & 80,76 \\
\hline Custo da Assistência Técnica & 283,07 \\
\hline Depreciação & $1.291,58$ \\
\hline Custo de Oportunidade & 840,95 \\
\hline Custo Fixo Total & $3.959,00 /$ mês \\
\hline
\end{tabular}

Fonte: Elaborado pelos autores

O custo fixo unitário, conforme se observa na Tabela 5, representa o resultado da divisão do somatório dos custos fixos $(R \$ 3.959,00)$ dividido pela estimativa feita anteriormente, de 2.872 disparos por mês. Assim, cada disparo a laser feito pela clínica em estudo contém $R \$ 1,37$ de custos fixos de acordo com os critérios de rateio prédeterminados. 
Impacto da gestão de custos na formação do preço de venda: o caso de uma Clínica

Dermatológica Rodrigo Fernandes Malaquias, Virginia Aparecida Castro, Tânia Regina Brasileiro Azevedo Teixeira

Quanto aos custos variáveis, tem-se que as ponteiras utilizadas para o disparo possuem vida útil em função do número de disparos realizados. Segundo o fornecedor do aparelho, as ponteiras apresentam uma vida útil de 85.000 disparos; conforme já mencionado anteriormente, o custo de aquisição das ponteiras foi de $R \$ 13.200,00$. Assim, cada disparo carrega também um custo variável de $R \$ 0,15$, que se refere ao desgaste da ponteira utilizada para tal procedimento. O custo de oportunidade relativo aos recursos investidos nessas ponteiras já foi calculado anteriormente.

De posse desses números, pode-se determinar o custo de cada disparo como sendo igual a $R \$ 1,53(1,37+0,15)$. A partir desse custo, fizeram-se duas simulações para o preço de venda, considerando as possíveis margens de ganho sobre o preço de venda: uma de $25 \%$ e outra de $50 \%$. O custo de cada área corporal foi obtido multiplicando-se a quantidade de disparos necessários a cada operação pelo custo de $\mathrm{R} \$ 1,53$. A Tabela 6 resume essas simulações.

Tabela 6: Preço de venda formado com base na estrutura de custos da empresa

\begin{tabular}{|c|c|c|c|c|c|}
\hline Área & $\begin{array}{c}\text { Média de } \\
\text { disparos } \\
\text { (unid.) }\end{array}$ & $\begin{array}{c}\text { Custo do } \\
\text { Disparo } \\
\text { (R\$) }\end{array}$ & $\begin{array}{c}\text { Custo do } \\
\text { Serviço } \\
\text { (R\$) }\end{array}$ & $\begin{array}{c}\text { Preço do } \\
\text { Serviço } \\
(\mathbf{2 5 \% )}-\mathbf{R \$}\end{array}$ & $\begin{array}{c}\text { Preço do } \\
\text { Serviço } \\
\mathbf{( 5 0 \% )}-\mathbf{R \$}\end{array}$ \\
\hline Antebraço & 292 & 1,53 & 447,88 & 597,18 & 895,77 \\
\hline Bochecha & 44 & 1,53 & 67,49 & 89,99 & 134,98 \\
\hline Buço & 69 & 1,53 & 105,84 & 141,11 & 211,67 \\
\hline Colo & 138 & 1,53 & 211,67 & 282,23 & 423,34 \\
\hline Face & 200 & 1,53 & 306,77 & 409,03 & 613,54 \\
\hline Mãos & 103 & 1,53 & 157,99 & 210,65 & 315,97 \\
\hline Nariz & 10 & 1,53 & 15,34 & 20,45 & 30,68 \\
\hline Olheira & 23 & 1,53 & 35,28 & 47,04 & 70,56 \\
\hline Pescoço & 119 & 1,53 & 182,53 & 243,37 & 365,06 \\
\hline Queixo & 69 & 1,53 & 105,84 & 141,11 & 211,67 \\
\hline
\end{tabular}

Fonte: Elaborado pelos autores

A Tabela 6 indica duas possibilidades de preço que podem ser praticados pela clínica ABC. Por exemplo, o valor de $\mathrm{R} \$ 597,18$ para a área do antebraço foi 
Impacto da gestão de custos na formação do preço de venda: o caso de uma Clínica Dermatológica Rodrigo Fernandes Malaquias, Virginia Aparecida Castro, Tânia Regina Brasileiro Azevedo Teixeira

encontrado dividindo-se $R \$ 447,88$ por 0,75 , pois deseja-se uma margem de $25 \%$ sobre o preço de venda. De posse desses valores, procedeu-se a uma comparação com os preços praticados pela clínica. A Tabela 7 mostra tal comparação.

Tabela 7: Comparação entre o preço de venda com base no mercado e com base nos custos

\begin{tabular}{|c|c|c|c|c|c|c|c|c|}
\hline \multirow[b]{2}{*}{ Área } & \multicolumn{4}{|c|}{ Margem de $25 \%$} & \multicolumn{4}{|c|}{ Margem de $50 \%$} \\
\hline & $\begin{array}{c}\text { Preço } \\
\text { Proposto }\end{array}$ & $\begin{array}{c}\text { Preço } \\
\text { Atual } \\
\text { Praticad } \\
0\end{array}$ & Dif.* & $\underset{\star \star \star}{\text { Dif. (\%) }}$ & $\begin{array}{c}\text { Preço } \\
\text { Proposto }\end{array}$ & $\begin{array}{c}\text { Preço } \\
\text { Atual } \\
\text { Praticado }\end{array}$ & Dif.* & $\underset{\star \star}{\text { Dif. (\%) }}$ \\
\hline $\begin{array}{c}\text { Antebraç } \\
0\end{array}$ & 597,18 & 650,00 & 52,82 & $8,13 \%$ & 895,77 & 650,00 & $(245,77)$ & $-37,81 \%$ \\
\hline $\begin{array}{c}\text { Bochech } \\
\text { a }\end{array}$ & 89,99 & 180,00 & 90,01 & $50,01 \%$ & 134,98 & 180,00 & 45,02 & $25,01 \%$ \\
\hline Buço & 141,11 & 180,00 & 38,89 & $21,60 \%$ & 211,67 & 180,00 & $(31,67)$ & $-17,60 \%$ \\
\hline Colo & 282,23 & 400,00 & 117,77 & $29,44 \%$ & 423,34 & 400,00 & $(23,34)$ & $-5,84 \%$ \\
\hline Face & 409,03 & 480,00 & 70,97 & $14,79 \%$ & 613,54 & 480,00 & $(133,54)$ & $-27,82 \%$ \\
\hline Mãos & 210,65 & 300,00 & 89,35 & $29,78 \%$ & 315,97 & 300,00 & $(15,97)$ & $-5,32 \%$ \\
\hline Nariz & 20,45 & 80,00 & 59,55 & $74,44 \%$ & 30,68 & 80,00 & 49,32 & $61,65 \%$ \\
\hline Olheira & 47,04 & 80,00 & 32,96 & $41,20 \%$ & 70,56 & 80,00 & 9,44 & $11,80 \%$ \\
\hline Pescoço & 243,37 & 300,00 & 56,63 & $18,88 \%$ & 365,06 & 300,00 & $(65,06)$ & $-21,69 \%$ \\
\hline Queixo & 141,11 & 180,00 & 38,89 & $21,60 \%$ & 211,67 & 180,00 & $(31,67)$ & $-17,60 \%$ \\
\hline
\end{tabular}

* Dif.: representa a diferença entre as colunas "Preço Atual Praticado" e "Preço Proposto";

** Dif. (\%): representa o porcentual da coluna "Dif." sobre a coluna "Preço Atual Praticado".

Fonte: Elaborado pelos autores.

Ao se comparar os preços formados com base em uma margem de $25 \%$ com os preços formados com base em uma cotação de mercado, constatou-se que os valores cobrados para todos os tipos de tratamento oferecidos pela clínica estavam acima do necessário para que a mesma obtivesse a citada rentabilidade. Partindo-se para uma margem maior, de 50\%, a constatação não foi a mesma. Conforme a Tabela 7 indica, em sete casos, se a margem fosse de $50 \%$, o preço de venda com base na estrutura de custos da clínica $A B C$ deveria ser superior ao que a clínica vem praticando; já para outras três áreas corporais indicam que, com essa margem, o preço a ser cobrado poderia ainda ser menor que o praticado até o momento. 
Impacto da gestão de custos na formação do preço de venda: o caso de uma Clínica

Com isso, verifica-se que o preço praticado pela clínica com base em uma cotação de mercado não está de acordo com a sua estrutura interna de custos, visto que, com uma margem de $25 \%$, as variações vão desde $8,13 \%$ até $74,44 \%$.

Se a margem for alterada para $50 \%$, as variações ficam dentro do intervalo de $37,81 \%$ e $61,65 \%$. Isso aponta para diferentes implicações, pois, caso a clínica deseje trabalhar com uma política de descontos, esta política só estará coerente com os custos incorridos pela empresa por fruto do acaso, pois a alocação de tais custos no preço de venda da clínica não é conhecida (ou pelo menos, até o momento, não eram).

$O$ principal ponto notado foi o seguinte: se a clínica $A B C$ se baseasse em sua estrutura de custos para a determinação do preço de venda, ela poderia praticar preços de alguns serviços a um valor inferior ao que o mercado cobra. Desta forma, obteria um diferencial competitivo em relação à concorrência, apresentando o potencial de atrair mais clientes e proporcionar uma maior acessibilidade da população a este serviço.

Por exemplo, considerando-se uma margem de retorno de $25 \%$ sobre o preço de venda, áreas como buço, bochecha e nariz poderiam ser precificadas por um valor bem menor e ainda assim manter uma rentabilidade aceitável para a empresa, visto que estas áreas demandam uma pequena quantidade de disparos para a execução do serviço.

Entretanto, ao analisar a margem de $50 \%$ sobre o preço de venda nota-se que para alguns procedimentos a clínica, ao basear sua estrutura de custos apenas no mercado, estaria incorrendo em prejuízo. Este fato pode ser observado principalmente em áreas corporais maiores como antebraço e face, as quais demandam uma maior quantidade de disparos do aparelho na execução do serviço. Assim, mostra-se uma das utilidades da análise de custos para a gestão das empresas.

\section{CONSIDERAÇÕES FINAIS}

De acordo com o apresentado na introdução deste trabalho, os preços de venda de uma empresa podem ser fixados: com base nos custos, no mercado ou em uma 
Impacto da gestão de custos na formação do preço de venda: o caso de uma Clínica

Dermatológica

Rodrigo Fernandes Malaquias, Virginia Aparecida Castro, Tânia Regina Brasileiro Azevedo Teixeira

combinação de ambos. Contudo, os preços praticados pelas empresas devem ser suficientes para cobrir seus custos, despesas, e ainda apresentar um retorno sobre o capital aplicado no empreendimento.

Diante dessas afirmações, procurou-se identificar a diferença entre o preço de venda formado com base no mercado e o preço de venda baseado na estrutura de custos. O estudo foi desenvolvido com base nos dados de uma clínica dermatológica, situada na região do Triângulo Mineiro. O objetivo específico deste artigo foi analisar se após o conhecimento de sua estrutura de custos, os preços praticados pela clínica deveriam sofrer alterações significativas.

Constatou-se que o preço que a clínica pratica, baseando-se em uma cotação de mercado, não está de acordo com sua estrutura interna de custos. Ao considerar uma margem de lucro de $25 \%$ sobre o preço de venda, as diferenças entre os dois preços cobrados variam desde $8,13 \%$ até $74,44 \%$. Para uma margem de $50 \%$, as variações ficam dentro do intervalo de $-37,81 \%$ e $61,65 \%$.

Lima, Egito e Silva (2004) constataram em seu estudo que as ferramentas utilizadas na gestão hoteleira, no que se refere aos custos, são inadequadas para uma tomada de decisão eficaz. Callado et al. (2005), em seu estudo com empresas paraibanas, identificou pouca preocupação dos gestores no acompanhamento e controle dos custos de produção. Na mesma linha, este estudo constatou que a gestão da clínica $A B C$ ignorava a sua estrutura de custos para a formação do preço de venda de seus serviços.

Isso implicou em uma precificação inadequada, gerando: i) caso a clínica deseje trabalhar com uma política de descontos, esta política só estará coerente com os custos incorridos pela empresa por fruto do acaso; e ii) a clínica $A B C$ poderia praticar preços de alguns serviços a um valor inferior ao que o mercado cobra, dado à sua estrutura de custos, obtendo assim um diferencial competitivo em relação à concorrência e apresentando o potencial de atrair um maior número de clientes e iii) a clínica $A B C$ poderia estar em prejuízo em algumas áreas ao se considerar a margem de $50 \%$. 
Impacto da gestão de custos na formação do preço de venda: o caso de uma Clínica

Dermatológica

Rodrigo Fernandes Malaquias, Virginia Aparecida Castro, Tânia Regina Brasileiro Azevedo Teixeira

Espera-se que este estudo contribua para a determinação dos custos em empresas prestadoras de serviços, tal como do impacto do conhecimento desses custos na formação do seu preço de venda. Sugere-se que, futuramente, sejam pesquisados pontos como: i) o percentual de clínicas prestadoras de serviços dermatológicos, de determinada região, que baseiam seus preços em sua estrutura de custos; e ii) o valor atribuído aos gestores de clínicas deste setor à informações sobre custos.

\section{REFERÊNCIAS}

ANDRADE, M. M. (2004). Como preparar trabalhos para cursos de pós-graduação: noções práticas. (6 ed.). São Paulo: Atlas.

ARAÚJO, A. M. P.; ASSAF NETO, A. (2003). A Contabilidade Tradicional e a Contabilidade Baseada em Valor. Revista Contabilidade \& Finanças. n. 33. p. 16-32. Set./Dez.

BRASIL. Lei $n^{\circ}$ 6.404, de 15 de dezembro de 1976. Dispõe sobre as sociedades por ações. Disponível em <http://www6.senado.gov.br/sicon>. Acesso em 05/mai/2008.

CALLADO, A. L. C.; MACHADO, M. R.; CALlADO, A. A. C.; MACHADO, M. A. V. (2005). Análise da gestão de custos e formação de preços em organizações agroindustriais paraibanas. In: $V$ CONGRESSO USP CONTROLADORIA E CONTABILIDADE. São Paulo. Anais...São Paulo: USP.

CATELLI, A. (2006). Introdução: o que é Gecon? In: CATELLI, A. (Coord.). Controladoria: uma abordagem da gestão econômica - Gecon. (2 ed.). 5. reimp. São Paulo: Atlas. p. 29-32.

CONSELHO FEDERAL DE CONTABILIDADE - CFC. Resolução no 750, de 29 de dezembro de 1993. Dispõe sobre os princípios fundamentais de contabilidade. Disponível em <http://www.cfc.org.br>. Acesso em 01/julho/2008.

FARIA, A. C. F.; SCHLINDWEIN, A. C.; KLANN, R. C. (2006). Formação do preço de venda dos fretes rodoviários de carga fracionada. In: VI CONGRESSO USP CONTROLADORIA E CONTABILIDADE. São Paulo. Anais...São Paulo: USP.

GOULART, B. (2002). Custo de Oportunidade: oculto na contabilidade, nebuloso na mente dos contadores. Revista Contabilidade \& Finanças. n. 30, p. 19-31. Set./Dez. 
Impacto da gestão de custos na formação do preço de venda: o caso de uma Clínica

Dermatológica

Rodrigo Fernandes Malaquias, Virginia Aparecida Castro, Tânia Regina Brasileiro Azevedo Teixeira

GUERREIRO, Reinaldo; SANTOS, Ariovaldo dos. (2006). As empresas que operam no Brasil estão pagando juros sobre o capital próprio? In: VI CONGRESSO USP CONTROLADORIA E CONTABILIDADE. São Paulo. Anais...São Paulo: USP.

LEONE, George Sebastião Guerra. (2000). Curso de contabilidade de custos. (2 ed.). São Paulo: Atlas.

LIMA, G. A. S. F.; EGITO, M. O. T.; SILVA, J. D. G. (2004). Utilização de informações de custos no processo gerencial: estudo comparativo entre a hotelaria do estado do Rio Grande do Norte e a região nordeste, sob a ótica da gestão econômico-financeira. Revista Contabilidade e Finanças - USP, São Paulo, Edição Especial, p. 106 - 116.

MACEDO, P. J. F. (1991). Perversos efeitos dos encargos financeiros no preço da venda. Caderno de Estudos, São Paulo, FIPECAFI - Setembro.

MARTINS, E. (2008). Contabilidade de custos. (9 ed.). 6. reimp. São Paulo: Atlas.

NEVES, César das. (1982). Análise de Investimentos: projetos industriais e engenharia econômica. Rio de Janeiro: Zahar Editores S.A.

PEREIRA, C. A.; OLIVEIRA, A. B. S. (2006). Avaliação de Resultados e Desempenhos. In: CATELLI, A. (Coord.) Controladoria: uma abordagem da gestão econômica - Gecon. (2 ed.). 5. reimp. São Paulo: Atlas. Cap. 14.

REIS, E. A. (2002). Valor da empresa e resultado econômico em ambientes de múltiplos ativos intangíveis: uma abordagem da gestão econômica. (Tese de Doutorado). São Paulo: FEA/USP.

SANTOS, A. (2007). Quem está pagando Juros Sobre o Capital Próprio no Brasil? Revista Contabilidade \& Finanças - USP. Edição 30 anos de Doutorado. p. 33-44. São Paulo: USP.

TROSTER, R. L.; MOCHÓN, F. (1999). Introdução à Economia. São Paulo: Makron Books.

VASCONCELLOS, M. S.; GARCIA, M. E. (2000). Fundamentos de Economia. São Paulo: Saraiva.

VICECONTI, P. E. V.; NEVES, S. (1995). Contabilidade de custos: um enfoque direto e objetivo. (4 ed.). São Paulo: Frase Editora.

Data de Submissão: 16/05/2010

Data de Aceite: 02/03/2011 
Apêndice A: Esquema básico do custeio por absorção

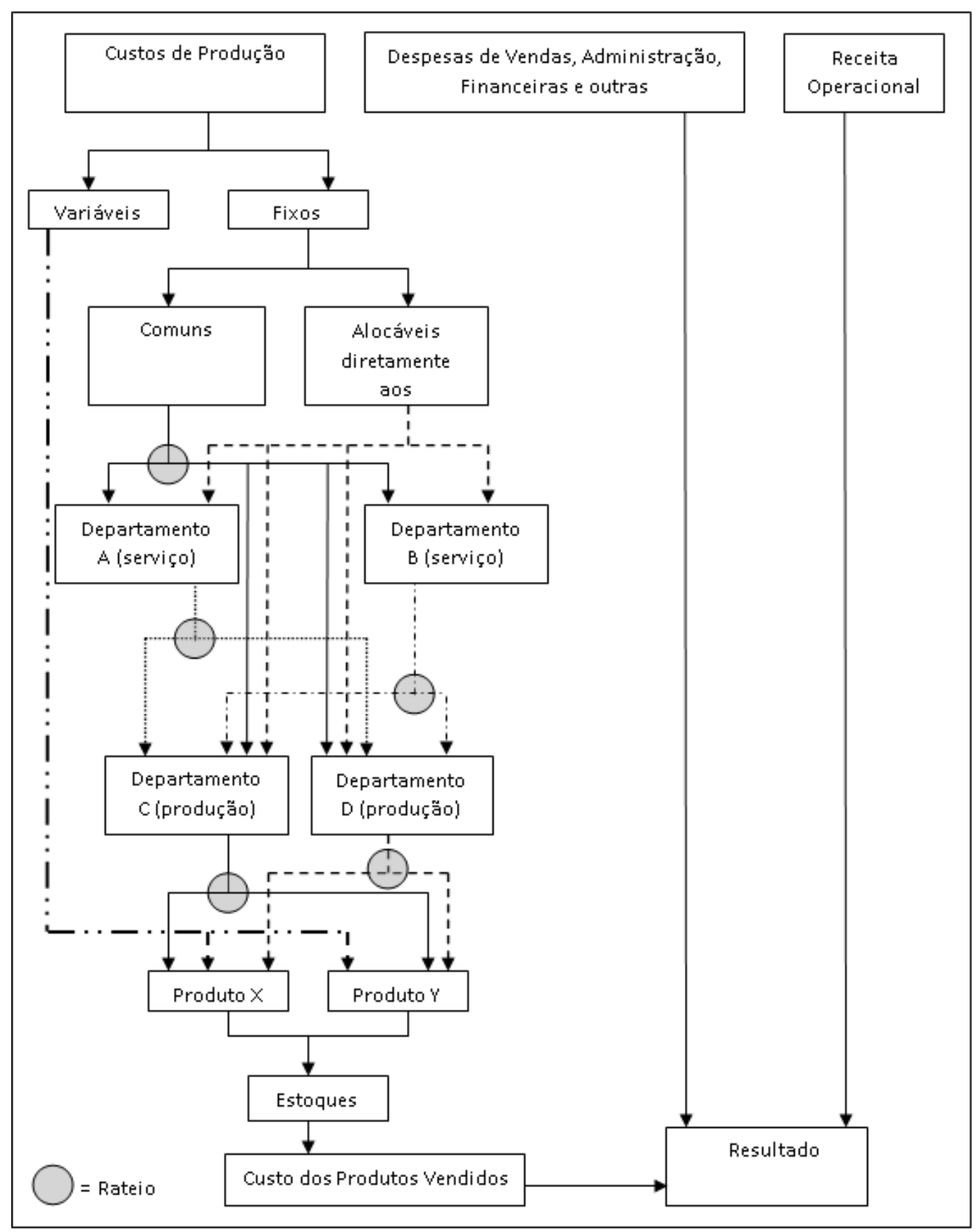

Fonte: Martins (2008, p. 74), com adaptações. 